\title{
Meningkatkan Hasil Belajar menggunakan Tipe Jigsaw pada Materi Jaringan Tumbuhan Siswa Kelas VIII SMPN 2 Pematang Karau dengan Media Leaflet
}

\section{Increasing Learning Outcome using Cooperative Learning Jigsaw Type in Secondary High School}

\author{
Amir $^{1 *}$, Muhammad Zaini ${ }^{2}$ \\ ${ }^{1}$,SMPN 2 Pematang Karau, Muara Plantau, Kabupaten Barito Timur, Kalimantan Tengah, Indonesia \\ ${ }^{2}$ Fakultas Keguruan dan Ilmu Pendidikan, Universitas Lambung Mangkurat, Banjarmasin, Indonesia \\ *Corresponding authors: amirpbios2@gmail.com
}

Manuscript received: Revision accepted:

\begin{abstract}
Classroom action research was conducted at SMP Negeri 2 Pematang Karau Pematang Karau Subdistrict, East Barito Regency. Problems experienced by teachers is on the learning process has not been maximized. There are 33 students of class VIII SMP Negeri 2 Pematang Karau, 8 students of whom are willing to interact actively. Learning outcomes average grade VIII students was 45. Whereas Minimum Competence Score is 75. This study result to improve learning outcomes using Jigsaw Type cooperative model on the topic of Plant systematics. The study was conducted two cycles. Based on the results it can be concuded that the implementation of Jigsaw cooperative learning can improve learning outcomes.
\end{abstract}

Keywords: learning outcome jigsaw, leaflet

\section{PENDAHULUAN}

Proses IPA ditujukan untuk mengembangkan kemampuan siswa untuk menemukan konsep melalui proses IPA yang mencakup: mengamati, membedakan, mengklasifikasi, memprediksi, menafsirkan, menerapkan konsep, merumuskan hipotesis, merencanakan penelitian, membuat model, berkomunikasi, dan menyimpulkan sesuai yang dikemukakan oleh Carin dalam (Indrawati, 2016: 33). Sehingga proses pembelajaran IPA sekarang berpusat kepada siswa bukan lagi bersumber pada guru.

Menurut Depdiknas, (2006: 3) salah satu fungsi pembelajaran IPA memupuk serta mengembangkan minat siswa terhadap IPA sehingga lebih menekankan agar siswa menjadi pembelajar aktif dan luwes agar tercapai hasil belajar yang optimal. Di sinilah peran guru sebagai agen perubahan. Guru berperan membangkitkan motivasi belajar siswa. Hal ini tergantung dari strategi pembelajaran yang diterapkan guru untuk menciptakan pembelajaran yang menyenangkan. Menurut UU RI No. 20 Tahun 2003, tugas guru adalah guru membantu peserta didik yang sedang berkembang untuk mempelajari sesuatu yang belum diketahuinya, membentuk kompetensi dan memahami materi standar yang dipelajari. Guru yang baik adalah guru yang memahami, menguasai dan menggunakan tipe dan media pembelajaran. Guru juga harus kreatif dalam menggunakan dan memanfaatkan tipe dan media pembelajaran, sehingga proses belajar mengajar mencapai harapan.

Kenyataannya sekarang kegiatan pembelajaran Ilmu Pengetahuan Alam (IPA) di sekolah dasar sering kali muncul tipe ceramah yang diterapkan guru dalam menyampaikan monoton, yang ditandai dengan aktivitas guru menerangkan, siswa mendengarkan apa yang disampaikan guru hingga proses belajar mengajar berakhir tanpa ada kesempatan untuk mengembangkan daya kreatifitas yang dimiliki siswa. Dengan kondisi seperti ini menyebabkan proses pembelajaran kurang kondusif, membosankan, serta membuat minat belajar siswa (Durandt, 2014:142). Selain itu pada saat guru selesai menjelaskan materi pelajaran guru memberikan kesempatan kepada siswa untuk bertanya seputar materi yang dibahas, namun tidak ada siswa yang bertanya hal ini disebabkan karena siswa merasa malu dan takut salah sehingga mereka memilih diam.

Hal serupa juga dialami oleh siswa kelas VIII SMPN 2 Pematang Karau pada materi jaringan tumbuhan. Siswa tidak begitu antusias mengikuti pelajaran, hal ini bisa dilihat dari 33 siswa kelas kelas VIII SMP Negeri 2 Pematang Karau hanya 8 siswa yang mau berinteraksi secara aktip. Hasil belajar siswa dalam pelajaran IPA pada saat ulangan rata-rata nilai siswa kelas VIII adalah 45 . padahal KKM (Kriteria Ketuntasan Minimal) yang ditetapkan adalah 75 .

Menurut (Sulistyowati, 2017:64) bahwa suasana kelas perlu direncanakan dan dibangun sedemikian rupa dengan menggunakan model pembelajaran yang tepat agar siswa dapat memperoleh kesempatan untuk berinteraksi satu sama lain sehingga pada gilirannya dapat diperoleh hasil belajar yang optimal. Pembelajaran tipe Jigsaw dianggap cocok diterapkan dalam pembelajaran IPA pada materi Jaringan tumbuhan, karena dengan tipe Jigsaw siswa diharapkan membagi pengetahuan yang diperolehnya 
dengan teman satu kelompoknya dan dapat meningkatkan kecakapan sosial pada masing masing anggota kelompok. Faktor lain rendahnya hasil belajar adalah kurangnya buku pelajaran yang dimiliki sekolah, yang timbulkan akibat banjir. Oleh karena itu, diperlukan media pembelajaran sebagai alat bantu dalam proses belajar mengajar dapat membangkitkan keinginan dan minat yang baru, membangkitkan motivasi dan rangsangan kegiatan belajar mengajar, dan bahkan membawa pengaruh psikologis terhadap siswa (Hutabarat, 2015:54). Pemakaian media pembelajaran yang digunakan adalah media leaflet yang merupakan bentuk penyampaian informasi melalui lembaran lipat yang isinya dapat dalam bentuk gambar dan kalimat (Gani, 2014:34). Menurut (Notoatmojo, dalam Kawuriansari, 2010:111) media leaflet mampu meningkatkan gairah belajar bagi siswa.

Berdasarkan uraian di atas penulis tertarik melakukan penelitian Tindakan Kelas (PTK) dengan judul "Upaya Meningkatkan Hasil Belajar Menggunakan Tipe Jigsaw pada Materi Jaringan Tumbuhan Siswa Kelas VIII SMPN 2 Pematang Karau dengan Media Leaflet".

\section{METODE PENELITIAN}

Metode yang digunakan dalam penelitian ini adalah metode Penelitian Tindakan Kelas atau PTK merupakan sebuah penelitian yang dilakukan oleh guru di kelas dengan jalan merancang, melaksanakan, merefleksi tindakan. Kehadiran peneliti sebagai guru di kelas sebagai pengajar tetap dan dilakukan seperti biasa, sehingga siswa tidak tahu kalau diteliti. Dengan cara ini diharapkan didapatkan data yang seobjektif mungkin demi kevalidan data yang diperlukan.

PTK merupakan siasat guru dalam mengaplikasikan pembelajaran dengan berkaca pada pengalamnya sendiri atau dengan perbandingan dari guru lain (Tahir, dalam Sukardiyono, 2015:4). Sedangkan menurut (Bahri, dalam Sukardiyono, 2015:4) menyatakan bahwa penelitian tindakan kelas merupakan sebuah kegiatan yang dilaksanakan untuk mengamati kejadian-kejadian dalam kelas untuk memperbaiki praktek dalam pembelajaran agar lebih berkualitas dalam proses sehingga hasil belajarpun menjadi lebih baik

Penelitian Tindakan Kelas (PTK) dilaksanakan di SMPN 2 Pematang Karau (Sekolah Terpencil) Kabupaten Barito Timur. Pada Tahun Pelajaran 2016/2017. Jalan Sungai Karau desa Muara Plantau Kecamatan Pematang Karau Provinsi Kalimantan Tengah. Pelaksanaan Penelitian Tindakan Kelas (PTK) dilaksanakan dalam dua siklus. Siklus pertama dilaksanakan pada tanggal 5 Oktober 2016 dan siklus kedua dilaksanakan pada tanggal 13 Oktober 2016. Setiap kali pertemuan membutuhkan waktu 70 menit dengan rincian 2 x 35 menit. Penelitian dilaksanakan sesuai dengan jadwal pelajaran.

Hasil tes akhir siklus diperiksa dan diberi skor. Siswa yang memperoleh nilai $\geq 75$ dinyatakan tuntas belajar karena KKM (Kriteria Ketuntasan Minimal) yang ditetapkan oleh sekolah adalah 75. Sedangkan ketuntasan klasikal dapat diketahui dengan menggunakan rumus:

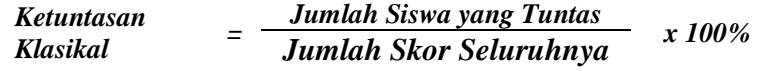

Menurut Depdiknas, dalam Tofan, (2015:57) menyatakan bahwa suatu kelas dikatakan tuntas belajarnya jika dalam kelas tersebut terdapat $\geq 85 \%$ telah tuntas belajarnya. Adapun skor penilaian observasi yang menggunakan skala 0-4, seperti disajikan dalam tabel 2.1 di bawah ini.

Tabel 1. Pedoman Penilaian Pelaksanaan Pembelajaran

\begin{tabular}{cc}
\hline Kategori & Bobot Skor \\
\hline Sangat tepat & 4 \\
Tepat & 3 \\
Cukup tepat & 2 \\
Kurang tepat & 1 \\
Tidak tepat & 0 \\
\hline
\end{tabular}

Sumber: Jihad dan Haris (2010:120).

Setelah diperoleh skor penilaian pelaksanaan pembelajaran maka dihitung untuk menentukan kualitas pelaksanaan pembelajaran menggunakan rumus:

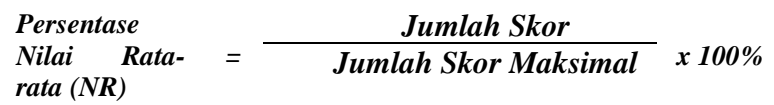

Tabel 2 Kriteria skor penilaian pelaksanaaan pembelajaran

\begin{tabular}{cl}
\hline Nilai $(\boldsymbol{\%})$ & Kriteria \\
\hline $90-100$ & Sangat baik \\
$70-89$ & Baik \\
$50-69$ & Cukup baik \\
$29-49$ & Kurang baik \\
$10-29$ & Tidak baik \\
\hline
\end{tabular}

Sumber: Jihad dan Haris (2012 : 131)

\section{HASIL DAN PEMBAHASAN}

Awalnya, Siswa tidak begitu antusias mengikuti pelajaran, yaitu pembelajaran satu arah dan didominasi oleh guru. Hal ini bisa dilihat dari 33 siswa kelas VIII SMP Negeri 2 Pematang Karau hanya 8 siswa yang mau berinteraksi secara aktip. Dalam kondisi seperti ini mengakibatkan hasil belajar siswa dalam pelajaran IPA pada saat ulangan ratarata nilai siswa kelas VIII adalah 45. padahal KKM (Kriteria Ketuntasan Minimal) yang ditetapkan adalah 75.

Setelah diujicobakan pada siswa, maka diperoleh ketuntasan belajar siswa pada materi Jaringan Tumbuhan dengan tipe Jigsaw media leaflet dapat dilihat pada tabel di bawah ini.

Tabel 3 Nilai Hasil Belajar Siswa Siklus 1

\begin{tabular}{cccc}
\hline \multicolumn{4}{c}{ Siklus 1 } \\
\hline \multicolumn{2}{c}{ Ketuntasan Belajar } & \multicolumn{2}{c}{ Nilai } \\
Tuntas & Tidak & Tertinggi & Terendah \\
23 & Tuntas & 92 & 40 \\
\hline
\end{tabular}

Dari tabel 3 di atas, diketahui siswa yang tidak tuntas sebanyak 10 siswa, dengan ketuntasan belajar adalah $70 \%$. Dari nilai yang diperoleh siswa dengan menggunakan 
pembelajaran tipe Jigsaw terlihat adanya peningkatan, tetapi nilai belajar belum mencapai ketuntasan klasikal.

Tabel 4. Nilai Hasil Belajar Siswa Siklus 2

\begin{tabular}{cccc}
\hline & \multicolumn{2}{c}{ Siklus 2 } & \\
\multicolumn{2}{c}{ Ketuntasan Belajar } & & Nilai \\
Tuntas & Tidak & Tertinggi & Terendah \\
& Tuntas & & \\
\hline
\end{tabular}

\begin{tabular}{llll}
\hline 29 & 4 & 92 & 64 \\
\hline
\end{tabular}

Siklus 2 diketahui siswa yang tidak tuntas sebanyak 4 siswa, dengan ketuntasan belajar adalah 89\%. Hal ini menunjukkan bahwa pada siklus 2 presentase Ketuntasan Klasikal siswa sudah dinyatakan tuntas.

Data observasi guru selama proses pembelajaran, Peneliti sebagai guru dan dibantu oleh 2 Guru sebagai observer dapat dilihat dari tabel 5 di bawah ini.

Tabel 5. Data Observasi Guru Selama Proses Pembelajaran Siklus 1 Pertemuan 1

\begin{tabular}{|c|c|c|}
\hline No. & Kegiatan & Skor \\
\hline 1 & Guru menyampaikan tujuan pembelajaran dan memotivasi siswa & 2 \\
\hline 2 & Guru menyajikan informasi kepada siswa baik dengan peragaan (demontrasi) atau teks. & 2 \\
\hline 3 & Guru menjelaskan siswa bagaimana cara membentuk kelompok belajar & 2 \\
\hline 4 & Guru membimbing kelompok-kelompok belajar pada saat mereka mengerjakan tugas & 2 \\
\hline 5 & Guru mengetes materi pelajaran atau kelompok menyajikan hasil-hasil pekerjaan mereka. & 2 \\
\hline \multirow[t]{3}{*}{6} & $\begin{array}{c}\text { Guru memberikan cara-cara untuk menghargai baik upaya maupun hasil belajar individu dan } \\
\text { kelompok }\end{array}$ & 3 \\
\hline & Jumlah & 13 \\
\hline & Skor penilaian pelaksanaaan pembelajaran & $54 \%$ \\
\hline
\end{tabular}

Berdasarkan tabel 5 di atas menunjukkan pembelajaran yang dilakukan di kelas VIII dengan pembelajaran tipe Jiksaw penilaian pelaksanaaan pembelajaran mengalami peningkatan dari pertemuan sebelumnya dengan kriteria skor adalah cukup baik yaitu $54 \%$ berada pada rentang nilai (50\%-56\%). Pada siklus 1 hanya dilakukan satu kali pertemuan.

Tabel 6. Data Observasi Guru Selama Proses Pembelajaran Siklus 2 Pertemuan 1

\begin{tabular}{ccc}
\hline No. & Kegiatan & Skor \\
\hline $\mathbf{1}$ & Guru menyampaikan tujuan pembelajaran dan memotivasi siswa & 4 \\
$\mathbf{2}$ & Guru menyajikan informasi kepada siswa baik dengan peragaan (demontrasi) atau teks & 4 \\
$\mathbf{3}$ & Guru menjelaskan siswa bagaimana cara membentuk kelompok belajar & 3 \\
$\mathbf{4}$ & Guru membimbing kelompok-kelompok belajar pada saat mereka mengerjakan tugas & 3 \\
$\mathbf{5}$ & Guru mengetes materi pelajaran atau kelompok menyajikan hasil-hasil pekerjaan mereka. & 3 \\
$\mathbf{6}$ & Guru memberikan cara-cara untuk menghargai baik upaya maupun hasil belajar individu dan kelompok & 3 \\
& Jumlah & 20 \\
& Skor penilaian pelaksanaaan pembelajaran & $83 \%$ \\
\hline
\end{tabular}

Tabel 7. Data Observasi Guru Selama Proses Pembelajaran Siklus 2 Pertemuan 2

\begin{tabular}{ccc}
\hline No. & Kegiatan \\
\hline $\mathbf{1}$ & Guru menyampaikan tujuan pembelajaran dan memotivasi siswa \\
$\mathbf{2}$ & Guru menyajikan informasi kepada siswa baik dengan peragaan (demontrasi) atau teks \\
$\mathbf{3}$ & Guru menjelaskan siswa bagaimana cara membentuk kelompok belajar \\
$\mathbf{4}$ & Guru membimbing kelompok-kelompok belajar pada saat mereka mengerjakan tugas \\
$\mathbf{5}$ & Guru mengetes materi pelajaran atau kelompok menyajikan hasil-hasil pekerjaan mereka. \\
$\mathbf{6}$ & Guru memberikan cara-cara untuk menghargai baik upaya maupun hasil belajar individu dan kelompok & 4 \\
& Jumlah & 4 \\
& & Skor penilaian pelaksanaaan pembelajaran \\
\hline
\end{tabular}

Pada Siklus 2 dalam dua kali pertemuan data observasi guru yaitu tabel 6 dan tabel 7 menunjukkan pemeningkatan dari $83 \%$ menjadi $96 \%$ yang artinya pada pertemuan berikutnya berada pada kriteria nilai sangat baik $(90 \%$ -
100\%). Adapun masukan dari kegiatan perbaikan dari teman sejawat pada saat mengobservasi keterlaksanaan pembelajaran digunakan untuk menilai pelaksanaan 
pembelajaran selama berlangsung dapat di lihat pada tabel

di bawah ini

Tabel 8. Saran dari teman sejawat

\begin{tabular}{cc}
\hline Pertemuan ke- & Saran-saran \\
\hline P-1 & $\begin{array}{c}\text { Langkah-langkah pembelajaran dituliskan sebelum dilisankan dan pembelajaran harus disampaikan dengan runtut } \\
\text { dan tegas, sehingga siswa dapat memahami dengan mudah., karena siswa akan tahu pembelajaran berikutnya. } \\
\text { Perhatikan batas waktu agar mampu mengurangi waktu yang tidak bermanfaat. } \\
\text { P-2 } \\
\text { P-3 } \\
\text { Bagi siswa yang tidak aktif bertanya, ditugaskan menjawab pertanyaan temannya. } \\
\text { Pada saat kerja kelompok, harus ada pembagian tugas bagi masing-masing anggota. }\end{array}$ \\
\hline
\end{tabular}

Saran yang diberikan dari teman sejawat pada setiap pertemuan telah dilakukan perbaikan pada pertemuan siklus berikutnya. Sedangkan saran yang paling menarik pada setiap pertemuan adalah pemanfaatan waktu yang dimiliki agar dapat digunakan untuk menyelesaikan tugastugas yang diberikan oleh guru secara maksimal. Menurut Sabri, (2012:1) menyatakan pencapaian keberhasilan ditentukan sejauhmana seseorang mampu mengalokasikan waktunya dan membuat skala prioritas dari pekerjaan itu.

\section{SIMPULAN DAN SARAN}

Berdasarkan hasil penelitian dan pembahasan, maka dapat disimpulkan bahwa Pembelajaran dengan menggunakan Tipe Jigsaw dapat meningkatkan hasil belajar siswa dari ketuntasan belajar 70\% meningkat menjadi adalah $89 \%$ pada materi jaringan tumbuhan siswa kelas VIII SMPN 2 Pematang Karau dengan media leaflet.

Saran yang dapat dituliskan pada penelitian ini adalah pembelajaran tipe Jigsaw supaya memperhatikan pengelolaan waktu dalam proses pembelajaran. Langkahlangkah pembelajaran harus disampaikan dengan runtut dan tegas, sehingga siswa dapat memahami dengan mudah.

\section{DAFTAR PUSTAKA}

Depdiknas. (2006). Kurikulum Tingkat Satuan Pendidikan. Jakarta: Departemen Pendidikan Nasional.

Durandt, S.W., Said, I., Ratman. (2014). Meningkatkan Hasil Belajar IPA Khususnya Materi Energi dan Perubahannya Melalui Pembelajaran Quantum Teaching di kelas V SDN Inpres Matamaling. Jurnal Kreatif Tadolaku online. Vol.(2) 3:142-153

Widoyo, E., Mardiyana, \& Tri Atmojo.K. (2013). Pengembangan Model Pembelajaran Group Investigation Berbantu Vidio Camtasia Pada Materi Peluang untuk Siswa SMA/MA Negeri Kabupaten Cilacap Tahun Pelajaran 2013/2014. Jurnal elektronik Penndidikan Matematika Vol.2, No.5. 478 - 490
Gani, H.A., Istiaji, E., Kusima, A.I.(2014). Perbedaan Efektivitas Leaflet dan Poster Produk Komisi Penanggulangan AIDS Kabupaten Jember dalam Perilaku Pencegahan HIV/AIDS. Jurnal IKESMA. Vol.(10) 1: 31-48.

Hutabarat, W., Napitupulu, R.S. (2015). Pengaruh Pembelajaran Kooperatif Tipe Jigsaw dengan Menggunakan LKS terhadap Hasil Belajar Kimia pada Pokok Bahasan Hidrokarbon. Jurnal Penelitian Bidang Pendidikan. Vol.(21) 1:53-58.

Indrawati, dkk. (2016). Pedagogi: Komunikasi Efektif. Modul Guru Pembelajan IPA SMP Kelompok Kompetensi H. Pusat Jakarta, P4TK. Direktorat Jenderal Guru dan Tenaga Kependidikan, Kementerian Pendidikan dan Kebudayaan.

Jihad, A., Haris, A. (2012). Evaluasi Pembelajaran. Yogyakarta: Multi Pressindo.

Kawuriansari, R., Fajarsari, D., Mulidah, S. (2010). Studi Efektivitas Leaflet terhadap Skor Pengetahuan Remaja Putri tentang Dismenorea di SMP Kristen 01 Purwukerto Kabupaten Banyumas. Jurnal Ilmiah kebidanan. Vol. (2) 1: 108-122.

Sabri, A. (2012). Pengelolaan Waktu dalam Pelaksanaan Pendidikan Islam. Jurnal Al-Ta'lim Jil.(1) 3: hlm.180187

Sukardiyono, T. (2015). Pengertian, Tujuan, Manfaat, Karakteristik, Prinsip dan Langkah-langka Penelitian Tindakan Kelas.

http://staffnew.uny.ac.id/upload/132048521/pengabdi an/makalah-ppm-ptk-2015.pdf, di akses 12 Februari 2016

Zhou, Q., Huang, Q., \& Tian, H. (2013). Developing Students Critical Thinking by Task- Based Learning in Chemistry Experimen Teaching. Creative Education Science Research 4 (12A), 40-45. 